\title{
Article
}

\section{Utilization of an Electrochemiluminescence Sensor for Atropine Determination in Complex Matrices}

Brown, Kelly, McMenemy, Moira, Palmer, Matthew, Baker, Matthew J., Robinson, David Wayne, Allan, Pamela and Dennany, Lynn

Available at https://clok.uclan.ac.uk/29855/

Brown, Kelly, McMenemy, Moira, Palmer, Matthew, Baker, Matthew J., Robinson, David Wayne orcid iconORCID: 0000-0002-0729-5011, Allan, Pamela and Dennany, Lynn (2019) Utilization of an Electrochemiluminescence Sensor for Atropine Determination in Complex Matrices. Analytical Chemistry, 91 (19). pp. 12369-12376. ISSN 0003-2700

It is advisable to refer to the publisher's version if you intend to cite from the work. http://dx.doi.org/10.1021/acs.analchem.9b02905

For more information about UCLan's research in this area go to http://www.uclan.ac.uk/researchgroups/ and search for < name of research Group>.

For information about Research generally at UCLan please go to http://www.uclan.ac.uk/research/

All outputs in CLoK are protected by Intellectual Property Rights law, including Copyright law. Copyright, IPR and Moral Rights for the works on this site are retained by the individual authors and/or other copyright owners. Terms and conditions for use of this material are defined in the policies page. 


\title{
Utilization of an Electrochemiluminescence Sensor for Atropine Determination in Complex Matrices
}

\author{
Kelly Brown, ${ }^{\dagger}$ Moira McMenemy, ${ }^{\dagger}$ Matthew Palmer, ${ }^{\dagger}$ Matthew J. Baker, ${ }^{\dagger}$ David W. Robinson, ${ }^{\ddagger}$ \\ Pamela Allan, ${ }^{\dagger}$ and Lynn Dennany*, ${ }^{\dagger}$ (i)
}

${ }^{\dagger}$ WestCHEM Department of Pure and Applied Chemistry, University of Strathclyde, Technology and Innovation Centre 99 George Street, Glasgow, G1 1RD, United Kingdom

${ }^{\ddagger}$ School of Forensic and Applied Sciences, University of Central Lancashire, Lancashire, PR1 2XT, United Kingdom

Supporting Information

\begin{abstract}
A major challenge within forensic science is the development of accurate and robust methodologies that can be utilized on-site for detection at crime scenes and can be used for analyzing multiple sample types. The recent expansion of electrochemical sensors to tackle this hurdle requires sensors that can undergo analysis without any pretreatment. Given the vast array of samples that are submitted for forensic analysis, this can pose a major challenge for all electrochemical sensors, including electrochemiluminescent (ECL)-based sensors. Within this contribution, we demonstrate the capacity for an ECL-based sensor to address this challenge and it is potential

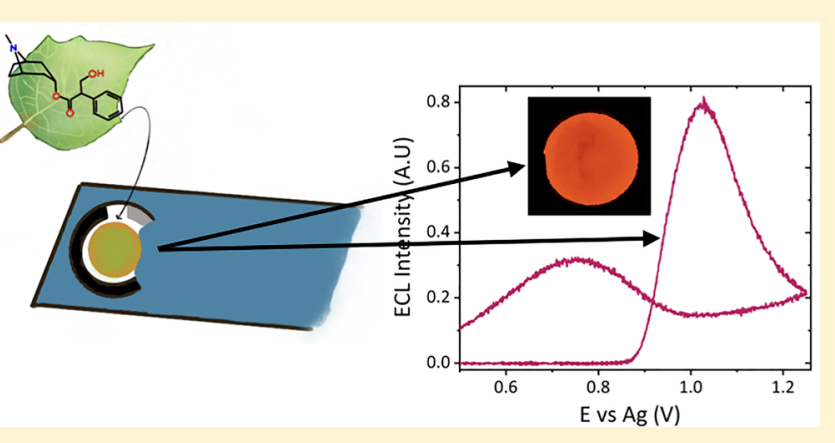
to detect and quantify atropine from a wide range of samples directly from herbal material to spiked solutions. This portable platform demonstrates satisfactory analytical parameters with linearity across a concentration range of 0.75 to $100 \mu \mathrm{M}$, reproducibility of $3.0 \%$, repeatability of $9.2 \%$, and a detection limit of $\sim 0.75 \mu \mathrm{M}$. The sensor displays good selectivity toward alkaloid species and, in particular, the hallucinogenic tropane alkaloid functionality within complex matrices. This portable sensor provides rapid detection alongside low cost and operational simplicity, thus, providing a basis for the exploitation of ECL-based sensors within the forensic arena.
\end{abstract}

$\mathrm{T}$ he exploitation of illicit substances continues to be a global issue further exacerbated by the ever changing nature of the global drug market. This has proved particularly challenging with the increasing presence of novel psychoactive substances (NPS). ${ }^{1-3}$ Traditional methodologies such as high performance liquid chromatography mass spectrometry (HPLC-MS) and gas chromatography mass spectrometry (GC-MS) remain the gold standard laboratory based analytical techniques in forensic analysis. However, there is a growing need for rapid, sensitive, and inexpensive detection systems for in-field analysis of both illicit substances and poisons in clinical and law enforcement environments. ${ }^{4}$ The main screening methods currently in use, which primarily consist of colorimetric presumptive tests whose color changes indicate the presence of a specific drug class, are often inadequate for NPS, while their poor selectivity hinders their reliability across all drug classes. ${ }^{4}$ In addition, these screening methods cannot be ascribed effectively to all forensic samples, limiting their use in-field. Electrochemical platforms such as electrochemiluminescence (ECL) can address these challenges, presenting a unique opportunity to address the current gap in forensic practices for rapid and crude identification of illicit and poisonous substances.

Atropine is a tropane alkaloid found within certain plants of the solanaceus family, including Datura and Atropa belladonna.
Its anticholinergic hallucinogenic behavior, due to its antagonist actions toward the acetylcholine receptors, makes the tropane alkaloid ideal as a poison, while its hallucinogenic effects make it appealing as a recreational drug. ${ }^{5}$ Atropine is considered one of the most important tropane alkaloids used for medical purposes, where it is employed for the treatment of Parkinson's disease ${ }^{6,7}$ to slow down the progression of myopia ${ }^{8}$ and as a treatment for organophosphate poisoning. ${ }^{9}$ In contrast to other popular naturally occurring recreational drugs, such as cannabis, atropine and scopolamine producing species remain largely unregulated in many countries; indeed, pharmaceutics containing the tropane alkaloid can often be obtained without a medical prescription. ${ }^{5}$

The use of atropine as a poison is not a novel concept, as is highlighted by the 1994 case of Dr. Paul Agutter. Dr Agutter, a biology professor at Edinburgh Napier University, attempted to murder his wife by spiking her gin and tonic with the deadly tropane alkaloid. Agutter subsequently attempted to divert suspicion by lacing multiple bottles of tonic, before returning the poisoned bottles to the supermarket shelf, resulting in mass panic when a number of people in the Edinburgh area fell ill. ${ }^{10}$

Received: June 26, 2019

Accepted: August 22, 2019

Published: August 22, 2019 
As mentioned, traditional methods for the identification of atropine and scopolamine, a structurally similar compound also found within Datura, typically involve HPLC, ${ }^{11}$ HPLC-MS, ${ }^{12}$ and GC-MS analyses. ${ }^{11,13}$ However, these methods suffer from significant instrument cost, lack of compatibility with the optimal extraction solvents, and poor portability. Furthermore, the complexity of such techniques requires the operator to have an expert working knowledge, posing a significant limitation for in-field or at scene testing. Exploration of ECL and cyclic voltammetry (CV) approaches both independently and as hyphenated systems have been reported. ${ }^{6,14-17}$ Although detection limits reported by these methods are typically greater than those achieved by HPLC-MS and GCMS ( $\mu \mathrm{M}$ compared with $\mathrm{nM}$ ), the versatility, portability, and ease of use of electrochemical methods make their use appealing, particularly for in-field applications. In addition, when considering the concentrations of $0.35 \mathrm{mM}$ to $1 \mathrm{mM}^{6}$ used by Paul Agutter did not result in any fatalities, it therefore becomes apparent that the higher concentrations required for effective poisoning and onset of symptoms could thus be easily detected utilizing basic electrochemical sensors. ${ }^{6}$

Although current electrochemical techniques have been applied to a wide variety of different sample matrices, including urine, ${ }^{16,18-20}$ blood, ${ }^{18,20}$ pharmaceutical preparations, ${ }^{17,19,21-23,6,19,22-24}$ and nonideal buffers such as CocaCola, ${ }^{6}$ to date no one has reported the direct detection of atropine within Datura plant species without prior separation strategies $^{14,15,24}$ or lengthy extraction procedures employed to isolate the tropane alkaloid species. ${ }^{22}$

Here we report on the proof-of-concept for the potential application of an ECL-based detection strategy, using atropine as a model alkaloid-based drug, on several potential forensic samples. We have shown for the first time the ability to directly detect a species within plant material through mechanical application onto an electrode surface, eliminating the need to perform any extraction procedures, thus, providing a proof-ofconcept for an in-field portable sensor using Datura to highlight potential applications of ECL sensors as drug screening tools with minimal sample preparation.

\section{EXPERIMENTAL SECTION}

Materials. Tris (2,2'-bipyridyl)-dichlororuthenium(II) hexahydrate $\left(\left[\mathrm{Ru}(\mathrm{bpy})_{3}\right] \cdot \mathrm{Cl}_{2} \cdot 6 \mathrm{H}_{2} \mathrm{O}\right)$, atropine sulfate monohydrate, lithium perchlorate $\left(\mathrm{LiClO}_{4}\right)$, and nafion $117(\sim 5 \%$ mixture of lower aliphatic alcohols and water) were purchased from Sigma-Aldrich. Absolute EtOH was purchased from VWR chemicals. All chemicals were used as received. All solutions were prepared in Milli-Q water $(18 \mathrm{~m} \Omega \mathrm{cm})$. Datura plant species were grown from seed in house and harvested as required. Solanum lycopersicum (tomato plant), Coca-Cola, and tonic water were commercially purchased.

Instrumentation. A CH instrument model 760D electrochemical analyzer was used for all electrochemical and electrochemiluminescence measurements. GSI Technologies Electrochemical carbon screen-printed electrodes (SPE) with a $4 \mathrm{~mm}$ carbon working electrode, carbon counter electrode, and Ag reference electrode were used for all electrochemical measurements with a $100 \mu \mathrm{L}$ sample volume. ECL emission was recorded via a Hamamatsu H10723-20 photomultiplier tube (PMT) enclosed within a light-tight Faraday cage. The PMT was positioned directly above the working electrode surface through the use of a specially designed sensor holder.
Fabrication of $\left[\mathrm{Ru}(\mathrm{bpy})_{3}\right]^{2+} / \mathrm{Nafion} \mathrm{ECL}$ Sensor. The $\left[\mathrm{Ru}(\mathrm{bpy})_{3}\right]^{2+} /$ nafion film modified carbon paste electrode was fabricated by the following procedure: A $1 \mathrm{mM}\left[\mathrm{Ru}(\mathrm{bpy})_{3}\right]^{2+}$ solution was prepared in 50:50 EtOH/ $\mathrm{H}_{2} \mathrm{O}$. A total of $5 \% \mathrm{w} / \mathrm{v}$ nafion was diluted to a concentration of $0.4 \% \mathrm{w} / \mathrm{v}$ with $50: 50$ $\mathrm{EtOH} / \mathrm{H}_{2} \mathrm{O}$. The final film concentration of $0.5 \mathrm{mM}$ $\left[\mathrm{Ru}(\mathrm{bpy})_{3}\right]^{2+}$ and $0.2 \%$ nafion was prepared by mixing the above solutions in a $1: 1(\mathrm{v} / \mathrm{v})$ ratio. Once prepared, the film was stored at $4{ }^{\circ} \mathrm{C}$. The carbon working electrode was dropcasted with $7 \mu \mathrm{L}$ of the film and left to air-dry for $2 \mathrm{~h}$ under darkness.

Preparation of Datura and Tomato Plant Samples. Datura and Solanum lycopersicum (tomato plant) material (used as a negative control) were either extracted prior to analysis or analyzed directly from harvest. Extractions were performed on approximately $50 \mathrm{mg}$ of air-dried plant material through ultrasonication in $10 \mathrm{~mL}$ of aqueous $\mathrm{LiClO}_{4}$ adjusted to $\mathrm{pH} 8$ for $30 \mathrm{~min}$. For direct detection within plant material, Datura or tomato leaf was mechanically applied to the modified electrode surface and $100 \mu \mathrm{L}$ of electrolyte cast on top to provide the required conductance.

\section{RESULTS AND DISCUSSION}

Electrochemical Characterization. The electrochemical behavior of atropine was interrogated on both unmodified and nafion confined $\left[\mathrm{Ru}(\mathrm{bpy})_{3}\right]^{2+}$-modified screen-printed carbon electrodes through CV. Figure 1a shows the typical voltammograms obtained for ruthenium-modified electrodes with $0.1 \mathrm{M}$ $\mathrm{LiClO}_{4}$ across multiple scan rates. The modified electrode displayed the expected anodic and cathodic peaks of the $\mathrm{Ru}^{2+}$ / $\mathrm{Ru}^{3+}$ couple at $\sim 0.95$ and $\sim 0.82 \mathrm{~V}$ versus $\mathrm{Ag}$, respectively. At sufficiently slow scan rates the peak-to-peak separation $\left(\Delta E_{\mathrm{p}}\right)$ is close to zero, the full width half-maximum (fwhm) is close to the theoretical value of $90.6 \mathrm{mV}$ for a one electron process of surface-confined species, ${ }^{25,26}$ and peak current varies linearly with the square root of the scan rate, as shown in the inset of Figure 1a. The broad non-Gaussian peaks and the nonzero $\Delta E_{\mathrm{p}}$ at higher scan rates highlight deviation from the ideal behavior of surface-confined species. This is not unexpected and has been previously reported for nafion-based [Ru$\left.(\text { bpy })_{3}\right]^{2+}$ films that display semi-infinite diffusion attributed to the cluster-type structure of nafion and slow mass transfer through the film accounting for the large $\Delta E_{\mathrm{p}}{ }^{27-29}$ However, this behavior is consistent with semi-infinite linear diffusion and the homogeneous charge transfer diffusion coefficient, $D_{\mathrm{CT}}$, is in good agreement with those values previously reported. $^{26,30}$

In contrast to previous studies, ${ }^{6,18-20,22}$ atropine displayed no distinctive electrochemical behavior at the concentrations of interest for the unmodified carbon screen printed electrodes across this potential range, as shown in Figure $1 \mathrm{~b}$. However, at higher concentrations, an anodic peak at $\sim 0.89 \mathrm{~V}$ was observed (see Figure S1). Atropine has previously been shown to produce an ECL response in the presence of $\left[\mathrm{Ru}(\mathrm{bpy})_{3}\right]^{2+}$ by undergoing a similar mediated oxidation process, as observed for an amine species of similar structure. ${ }^{16,31-36}$ By undergoing mediated oxidation via homogeneous electron transfer between the $\mathrm{Ru}^{3+}$ generated in situ and atropine within solution. The occurrence of the mediated oxidative process resulting in oxidation of atropine and the subsequent ECL response can be further confirmed by interrogation of the $\mathrm{CV}$ signals observed at the ruthenium-modified electrode at different atropine concentrations. As the concentration of 

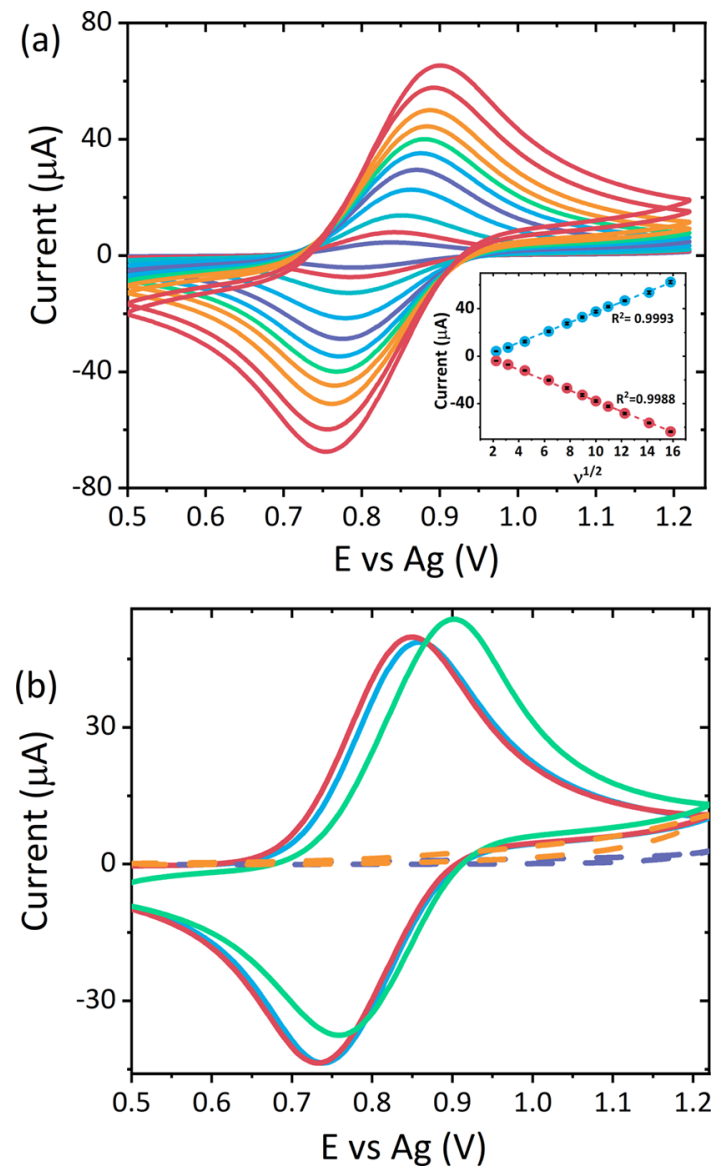

Figure 1. (a) $\mathrm{CV}$ responses of a ruthenium-modified electrode between 5 and $250 \mathrm{mV} \mathrm{s}^{-1}$ in $0.1 \mathrm{M} \mathrm{LiClO}_{4}$ over a potential range of $0.5 \leq \nu \leq 1.22 \mathrm{~V}$ vs Ag. The inset shows the linear dependence of current against $\nu^{1 / 2}$. (b) Typical $\mathrm{CV}$ responses obtained from an unmodified SPE carbon electrode with $50 \mu \mathrm{M}$ atropine sulfate (orange) and without (purple), ruthenium film modified electrode with no coreactant (blue) and in the presence of $50 \mu \mathrm{M}$ atropine sulfate (pink), and $1 \mathrm{mM}$ atropine sulfate (green) at a scan rate of 100 $\mathrm{mV} \mathrm{s}^{-1}$ over the potential range $0.5 \leq \nu \leq 1.22 \mathrm{~V}$ vs Ag with $0.1 \mathrm{M}$ $\mathrm{LiClO}_{4}$ as the electrolyte.

atropine increases, the oxidation peak of the $\mathrm{Ru}^{3+}$ species grows, while the reduction peak for the regeneration of the $\mathrm{Ru}^{2+}$ species decreases, as shown by Figure $1 \mathrm{~b}$. This behavior is consistent with electrochemical reactions, which are mediated by $\mathrm{Ru}^{3+}$ centers. ${ }^{37}$ As the oxidation route of atropine is not kinetically favorable at the electrode surface, it mainly proceeds via the $\mathrm{Ru}^{3+}$ centers to generate ECL emission shown in Figure 2. As such, there are fewer $\mathrm{Ru}^{3+}$ species available to undergo reduction to regenerate $\mathrm{Ru}^{2+}$ on the reverse scan. As such, the reduction current is observed to decease as the atropine concentration, and hence, consumption of $\mathrm{Ru}^{3+}$ increases.

ECL Detection of Atropine. Mechanisms recently suggested for the production of atropine ECL signals propose a cyclic reaction mechanism, seeing the regeneration of atropine alongside $\mathrm{Ru}^{2+} \cdot{ }^{17}$ However, here we observed the oxidation of atropine to be a chemically irreversible process, where the electro-oxidation of atropine results in the generation of formaldehyde and likely formation of a secondary amine at the tropane ring system as a result of electrolytic $N$-dealkylation. The presence of formaldehyde was confirmed through the Hehner's test, ${ }^{38}$ where prior to any electrochemical reactions, atropine produced a negative result,

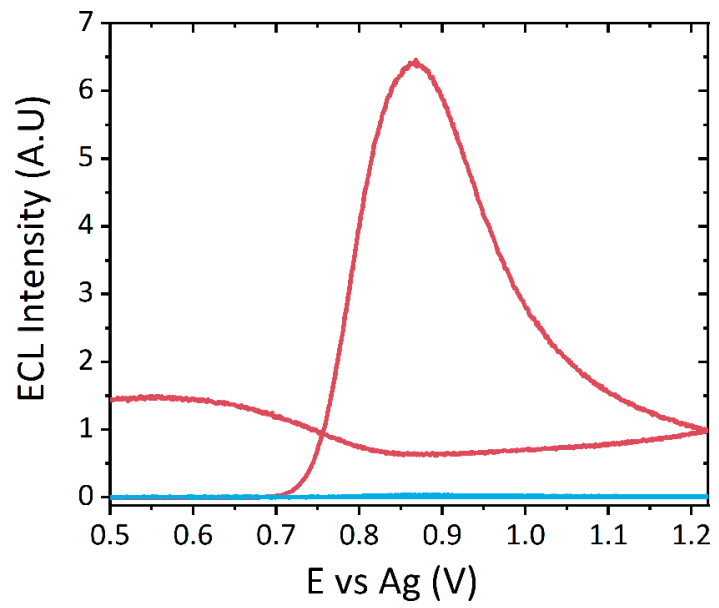

Figure 2. ECL signals recorded simultaneously with the modified electrode traces from Figure 1a at a PMT setting of $0.5 \mathrm{~V}$.

but following the generation of ECL, a violet ring was formed at the interface between the milk and $\mathrm{H}_{2} \mathrm{SO}_{4}$ containing trace amounts of potassium persulfate. Our proposed oxidativereduction mechanism is shown in eqs $1-5$, where the $\mathrm{Ru}^{3+}$ species generated at the electrode surface oxidizes atropine, following eq 2 , forming the highly reducing intermediated atropine (a neutral radical species (b)). This intermediate acts as the coreactant, generating the excited $\mathrm{Ru}^{2+*}$ state through homogeneous electron transfer, which in turn generates the imminium cation (c) as the product. Electrolytic N-dealkylation, shown in Scheme 1, then occurs forming formaldehyde (f) and the secondary amine species noratropine (e) via hydrolysis producing $(\mathrm{d})$ and subsequent decomposition of the imminium cation. This dealkylation mechanism is consistent with those previously reported by Leroy et al. ${ }^{21}$ and Bagheri et al. ${ }^{19}$ for the electro-oxidation of atropine via $\mathrm{CV}$ and with those observed for the electrochemical oxidation of tropanes and aliphatic tertiary amines. ${ }^{39,40}$

Effect of $\mathrm{pH}$ on ECL Response. $\mathrm{pH}$ influences the ECL response of atropine and similar amine species, where the greatest signal is obtained at values close to its $\mathrm{p} K_{\mathrm{a}}{ }^{16,17,23,35}$ The influence on $\mathrm{pH}$ was investigated between $\mathrm{pH} 5$ and $\mathrm{pH}$ 11 at an atropine concentration of $50 \mu \mathrm{M}$. The ECL signal increased from $\mathrm{pH} 5$ to $\mathrm{pH} \mathrm{8,} \mathrm{reaching} \mathrm{a} \mathrm{maximum} \mathrm{at} \mathrm{pH} 8$, which is close to the reported $\mathrm{p} K_{\mathrm{a}}$ value of 9.85 and as such was chosen as the optimum $\mathrm{pH}$ upon which all further analyses were performed. ${ }^{41}$ A further increase in $\mathrm{pH}$ above 8 resulted in a dramatic decrease in signal, before an increase was observed at $\mathrm{pH} \mathrm{11}$, see Figure 3a. Upon reaching $\mathrm{pH}$ 9, the alkaline conditions likely lead to a signal decrease due to a quenching effect as a result of a side reaction between the hydroxyl anions and the generated $\left[\mathrm{Ru}(\mathrm{bpy})_{3}\right]^{3+}{ }^{16}$ The subsequent increase in signal at $\mathrm{pH} 11$ and the broadening of this peak suggest the emergence of a second electroactive species. The appearance of this second species is thought to be the result of a basecatalyzed degradation of atropine in the presence of a high concentration of hydroxide ions, likely leading to the formation of tropine and tropic acid. ${ }^{42}$ The ECL responses observed for tropine and tropic acid can be found in Figure S2.

$$
\begin{aligned}
& {\left[\mathrm{Ru}(\mathrm{bpy})_{3}\right]^{2+} \leftrightarrow\left[\mathrm{Ru}(\mathrm{bpy})_{3}\right]^{3+}+\mathrm{e}^{-}} \\
& {\left[\mathrm{Ru}(\mathrm{bpy})_{3}\right]^{3+}+\text { atropine } \rightarrow \text { atropine }{ }^{\bullet+}+\left[\mathrm{Ru}(\mathrm{bpy})_{3}\right]^{2+}}
\end{aligned}
$$


Scheme 1. Schematic Detailing the Electrolytic N-Dealkylation Mechanism for Atropine During the ECL Process
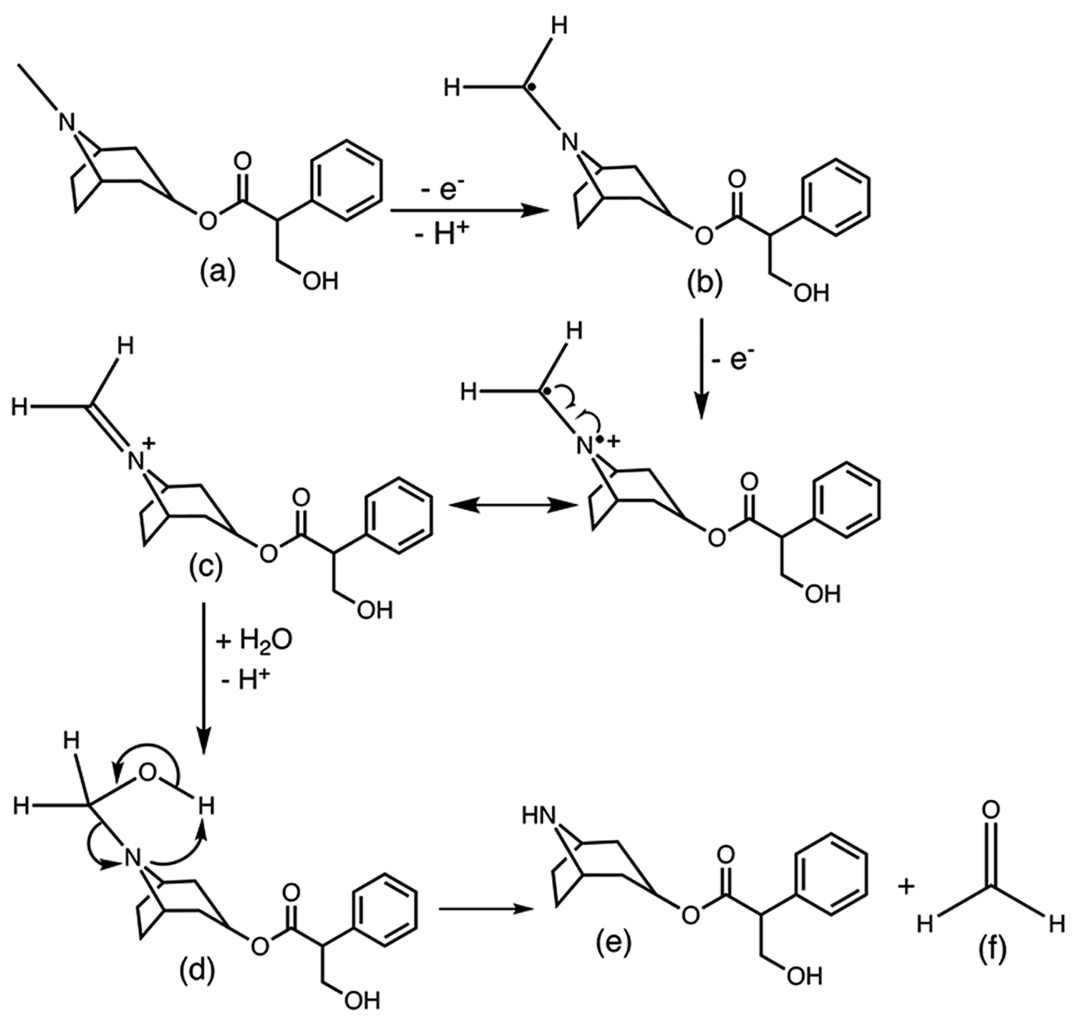

$$
\begin{aligned}
& \text { atropine }^{\bullet+} \rightarrow \text { atropine } \\
& {\left[\mathrm{Ru}(\mathrm{bpy})_{3}\right]^{3+}+\text { atropine }^{\bullet} \rightarrow\left[\mathrm{Ru}(\mathrm{bpy})_{3}\right]^{2+*}+(\mathrm{e})+(\mathrm{f})}
\end{aligned}
$$

$$
\left[\mathrm{Ru}(\mathrm{bpy})_{3}\right]^{2+*} \rightarrow\left[\mathrm{Ru}(\mathrm{bpy})_{3}\right]^{2+}+h \nu
$$

Influence of Atropine Concentration. The impact of atropine concentration on ECL response was investigated across a concentration range of 0.75 to $100 \mu \mathrm{M}$. This range is comparable to those previously reported for the detection of atropine via electrochemical methodologies $6,16,17,22$ in addition to those achieved via chemiluminescence. ${ }^{43}$ Furthermore, this range covers the concentrations observed for different Datura species. ${ }^{44}$ As the concentration increased, the ECL signal in turn increased as shown in Figure 4. In addition to the increase in signal, a shift in potential is observed as atropine concentration increases. This shift, although unexpected, can likely be attributed to a combination of the following effects: first, the ruthenium becomes the rate limiting reagent, where the $\mathrm{Ru}^{3+}$ centers are more rapidly consumed than produced via heterogeneous oxidation at the electrode surface. ${ }^{45}$ Second, a slight shift in $\mathrm{pH}$ at the electrode surface as a result of the increased concentration of the electrogenerated byproducts: noratropine and formaldehyde. This is consistent with previous work, which saw a shift in the $\lambda_{\text {ECLmax }}$ at a graphite electrode, ${ }^{46}$ highlighting the impact that $\mathrm{pH}$ can have. Further research, however, would be required to fully assess the impact to the sensor as a result of these effects. The response at maximum intensity was observed to be linearly proportional to atropine concentration with a coefficient $R^{2}$ value of 0.997 (Figure 4, inset), with a detection limit of $\sim 0.75 \mu \mathrm{M}(\mathrm{S} / \mathrm{N}=3)$. Instrument precision, sensor reproducibility, and repeatability was determined across six replicate measurements, six electrodes, and six days at an atropine concentration of 50 $\mu \mathrm{M}$ and found to be $4.5 \%, 3.0 \%$, and $9.2 \%$, respectively.

Sample Analysis. To demonstrate the wide potential scope of applications possible with the developed sensor, analysis of a variety of different matrices encountered within "real world" applications was performed, including plant material and drink samples. We report here for the first time a direct analysis method of Datura plant extracts alongside herbal material through mechanical application to the electrode surface without any prior separation or extraction techniques required. Despite the large number of species present alongside the tropane alkaloids, demonstrated in the LC-MS analysis of the leaf material performed (see Figure S3), no interference was observed in either the CV (see Figures 5a and S4) or ECL analysis obtained for the extracts (Figure 5b) or mechanical application (Figure $5 \mathrm{c}$ ) outside of the potential region for oxidation of the tropane alkaloid species, with an ECL signal observed at approximately the same potential seen for atropine sulfate within the $\mathrm{LiClO}_{4}$ electrolyte. To ensure the signals obtained were not impacted by the vast number of species present within the complex herbal matrix, leaves from a tomato plant were used as a control. Tomato plants come from the same plant family as Datura, the solanaceous family, but do not contain the hallucinogenic compounds of interest: atropine and scopolamine. Despite the control species not containing the hallucinogenic tropane alkaloids, a slight signal is still observed. This is believed to arise as a result of the naturally occurring glycoalkaloids found within all members of the solanaceous family. ${ }^{47}$ The particular glycoalkaloid found within tomato plants is the steroid alkaloid tomatine, containing the piperidine alkaloid functionality. ${ }^{47}$ It is therefore proposed that this functionality will result in the observed ECL signal, as is observed for other structurally similar amine species previously 

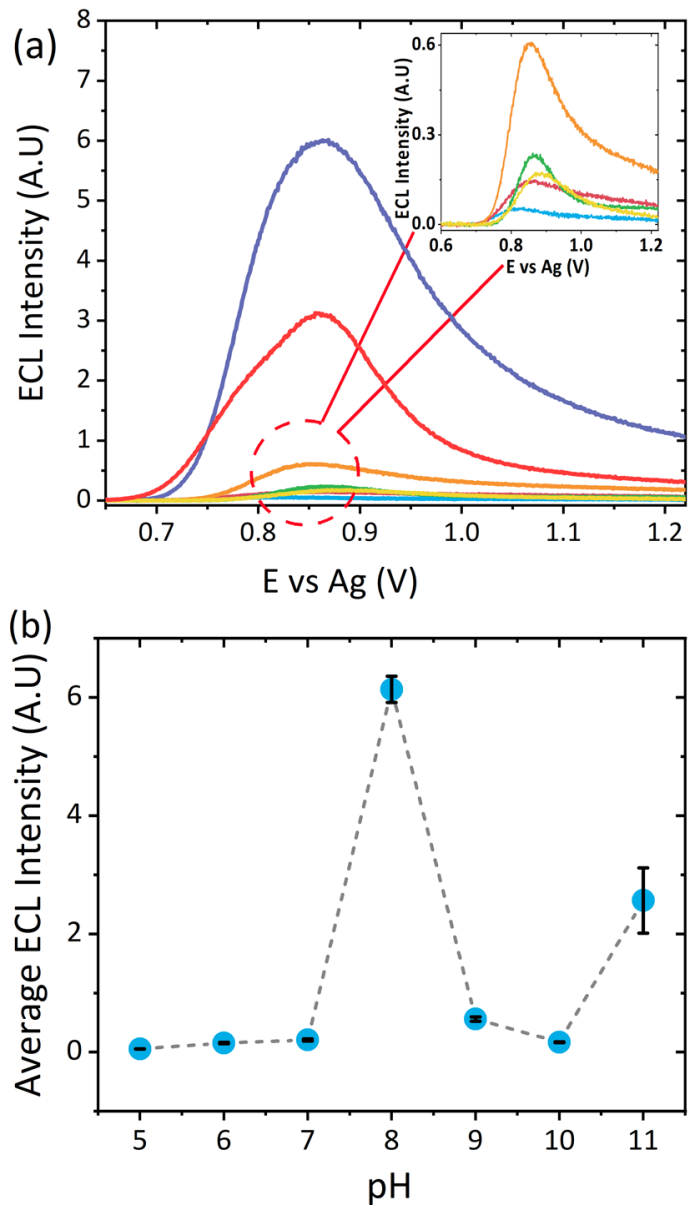

Figure 3. (a) ECL response of $50 \mu \mathrm{M}$ atropine sulfate between $\mathrm{pH}$ $5-11$ at a scan rate of $100 \mathrm{mV} \mathrm{s}^{-1}$ over the potential range $0.5 \leq \nu \leq$ $1.22 \mathrm{~V}$ vs Ag at a PMT setting of $0.5 \mathrm{~V}$ with $0.1 \mathrm{M} \mathrm{LiClO}_{4}$ as the electrolyte. (b) Trend in ECL response with $\mathrm{pH}$ across triplicate measurements.

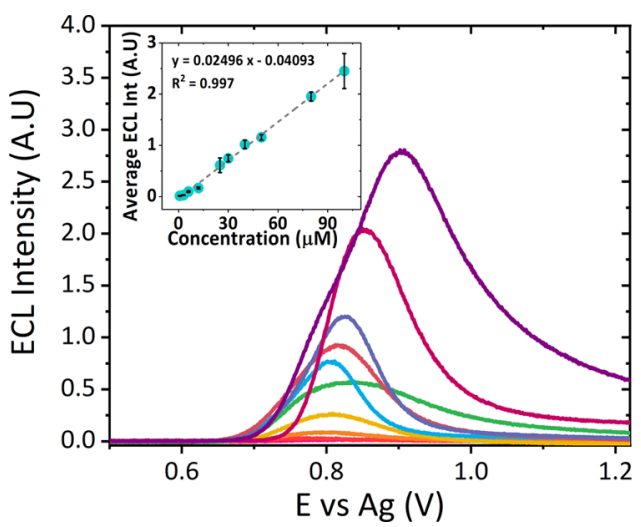

Figure 4. Dependence of ECL signal on atropine sulfate concentration between 0.75 to $100 \mu \mathrm{M}$ in $\mathrm{pH} 80.1 \mathrm{M} \mathrm{LiClO}_{4}$ at a scan rate of $100 \mathrm{mV} \mathrm{s}^{-1}$ across a potential range of 0.5 to $1.22 \mathrm{~V}$ vs Ag at a PMT setting of $0.45 \mathrm{~V}$. Inset shows the trend of maximum ECL signal against atropine sulfate concentration.

reported. ${ }^{16,31-36}$ The emission onset of tomatine is seen to begin at a lower potential than atropine, attributed to the oxidation occurring at a the secondary amine within the piperidine alkaloid rather than a tertiary amine as is present within the tropane alkaloid functional groups. To further assess
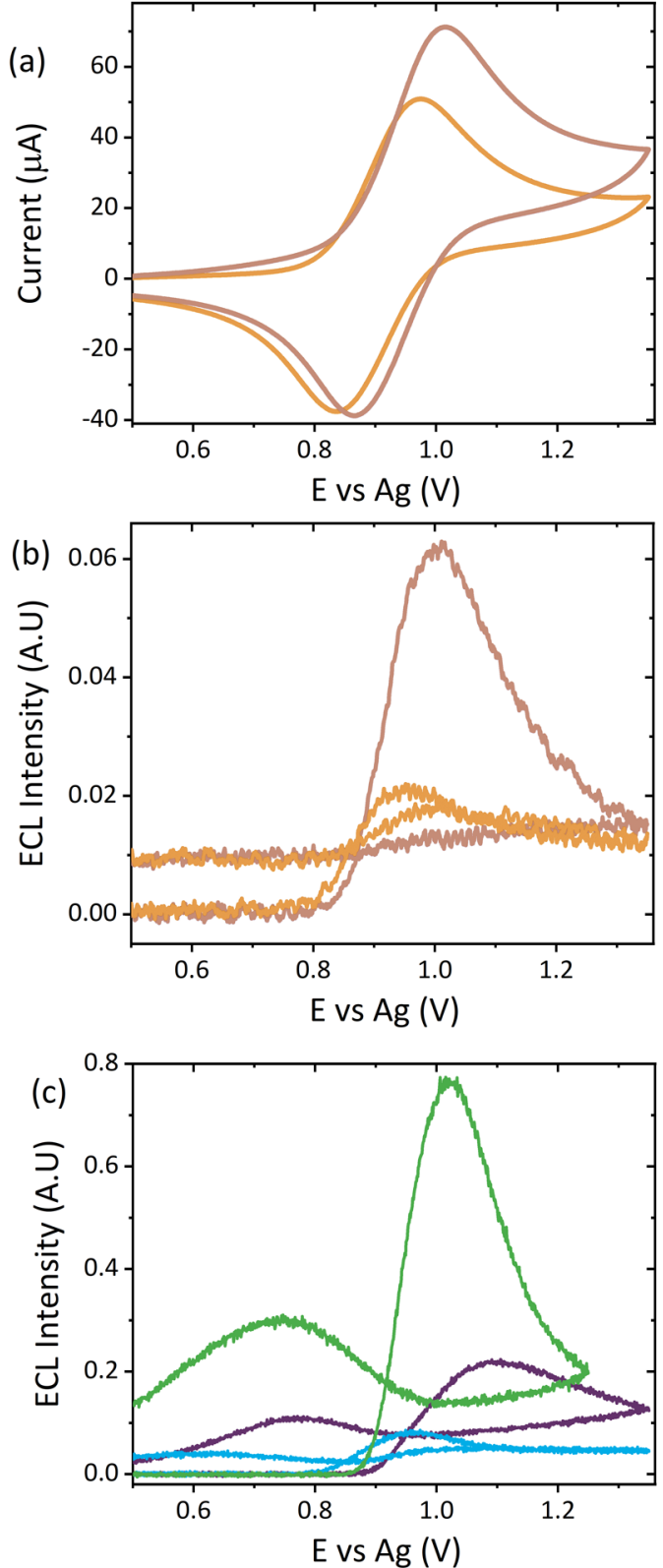

Figure 5. (a) CV responses obtained for Datura leaf (pink) and tomato leaf (yellow) extracts with $\left[\mathrm{Ru}(\mathrm{bpy})_{3}\right]^{2+}$-modified electrode at a scan rate of $100 \mathrm{mV} \mathrm{s}^{-1}$ over the potential range $0.5 \leq \nu \leq 1.36 \mathrm{~V}$ vs $\mathrm{Ag}$ with $0.1 \mathrm{M} \mathrm{LiClO}_{4}$ as the extraction solvent and electrolyte. (b) ECL responses recorded simultaneously with (a) at a PMT setting of $0.45 \mathrm{~V}$. (c) ECL responses obtained for mechanical application of mature Datura leaf (green), young Datura leaf (purple), and tomato leaf (blue) material onto $\left[\mathrm{Ru}(\mathrm{bpy})_{3}\right]^{2+}$-modified electrode surface with $0.1 \mathrm{M} \mathrm{LiClO}_{4}$ dropcast on top as the electrolyte, a scan rate of $100 \mathrm{mV} \mathrm{s}^{-1}$ and a PMT setting of $0.45 \mathrm{~V}$.

selectivity of the developed sensor an interferent study was performed with other naturally occurring alkaloids present within Datura species. These interferents included scopolamine, the second hallucinogenic tropane alkaloid present within Datura and the naturally occurring alkaloid solanine present within all plants of the solanaceous family. These were assessed against the signals observed for tomatine, $\mathrm{LiClO}_{4}$, atropine, and Datura and can be found within Figure 6. As shown, the signal observed from the solanine species is comparable to that observed for $\mathrm{pH} 8 \mathrm{LiClO}_{4}$ blank and, as 


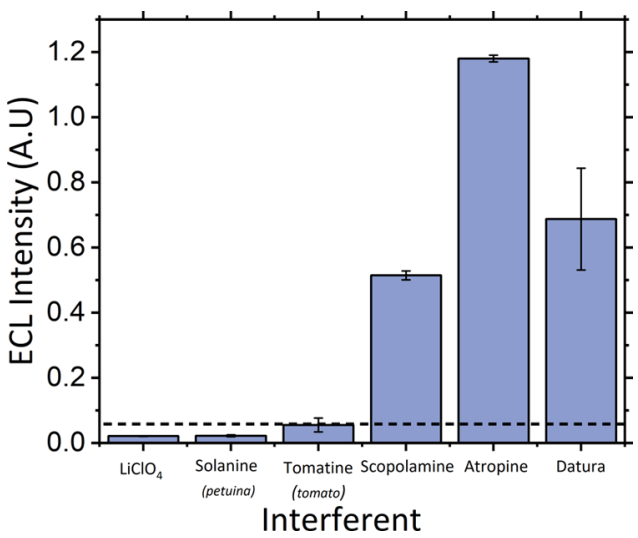

Figure 6. Maximum ECL responses observed using the proposed sensor in the presence of different species naturally found within the herbal material of the solanaceous family and compared against the signals observed for atropine sulfate in $\mathrm{LiClO}_{4}$ and Datura. The dotted line represents the threshold signal used to correct calculated concentrations of the alkaloids within the herbal material analyzed.

such, is not believable to interfere with the signal obtained from the herbal material. The tomatine signal is, however, slightly larger at an intensity of 0.05 A.U., which may be a result of the secondary amine species present compared with the tertiary amine within solanine. Thus, to account for the impact the glycoalkaloids may have on the observed Datura signal, the concentrations reported in Table 1 were calculated,

Table 1. Noncorrected and Corrected Alkaloid Concentrations Estimated from Extracts (E) and Mechanically Applied Samples (M) Obtained from ECL Analysis of Tomato and Young and Mature Datura Plants, Where Corrections Were Performed through Subtraction of the Tomatine Threshold Signal

\begin{tabular}{ccccc} 
& $\begin{array}{c}\text { ECL } \\
\text { intensity } \\
\text { (A.U.) }\end{array}$ & $\begin{array}{c}\text { corrected ECL } \\
\text { intensity (A.U.) }\end{array}$ & $\begin{array}{c}\text { noncorrected } \\
\text { salkaloid] } \\
(\mu \mathrm{M})\end{array}$ & $\begin{array}{c}\text { corrected } \\
\text { [alkaloid] } \\
(\mu \mathrm{M})\end{array}$ \\
$\begin{array}{c}\text { tomato } \\
\text { leaf (E) } \\
\text { tomato } \\
\text { leaf (M) }\end{array}$ & 0.0213 & 0 & 2.49 & 0 \\
$\begin{array}{c}\text { Datura (E) } \\
\text { mature } \\
\text { Datura } \\
\text { (M) }\end{array}$ & 0.0818 & 0 & 4.92 & 0 \\
$\begin{array}{c}\text { young } \\
\text { Datura } \\
(\mathrm{M})\end{array}$ & 0.683 & 0.0357 & 3.07 & 3.07 \\
\hline
\end{tabular}

subtracting this threshold response from the overall ECL signal observed for herbal material. This does represent a limitation of the proposed system; however, this is outweighed by the potential screening ability of this portable ECL approach and the rapid results that can be obtained.

Although this current study focuses on the detection of atropine, it can be clearly seen from Figure 6 that one of the closely related tropane alkaloid compounds, scopolamine, also generates a significant ECL emission. We know from the LCMS analysis (see Figure S3) performed on our Datura material that both atropine and scopolamine are present. These two compounds only differ by one epoxide group and are, as such, observed to oxidize at similar potentials, although scopolamine is observed to oxidize at a slightly later potential than atropine.
Therefore, it can be determined that the signals observed from the herbal material analyzed here are likely a combination of emission as a result of both tropane alkaloids atropine and scopolamine acting as coreactants. Current research is examining how to interrogate and extrapolate the impact on the overall signal which scopolamine contributes. This is currently underway with the ability to differentiate between the two species also under investigation. Despite this likely interferent effect, as the signals obtained within the herbal material lie within the same potential range identified for both atropine and scopolamine, we are confident in our identification of the presence of hallucinogenic tropane alkaloids within this material. Adding further confidence is the significantly larger signal observed within the herbal material compared with those obtained for the other naturally occurring nonhallucinogenic glycoalkaloids present within members of the solanaceous family, thus, ensuring the observed signals are not a result of the other species naturally found within herbal material.

Analysis within alternative complex matrices of commonly encountered carbonated drinks were performed to simulate a "real-world" scenario, which may be encountered within a forensic case involving potential drink spiking. Coca-Cola, a common mixer, and tonic water, the drink chosen by Paul Agutter in the attempted murder of his wife, were spiked to a final concentration of $50 \mu \mathrm{M}$ atropine sulfate. To emphasize the field applicability of this protocol, spiked drink samples were diluted with the electrolyte to produce an ideal sample matrix and ran alongside neat samples that replicate a potential "real-world" matrix. The natural acidity of Coca-Cola and tonic water, at $\sim \mathrm{pH} 2$, prevented the detection of atropine within raw samples; refer to Figure S5 for the corresponding $\mathrm{CV}$ and ECL signals.

As demonstrated in Figure 3, at acidic pH values, minimal ECL signal is obtained for atropine, attributed to the protonated form of the alkaloid dominating at these $\mathrm{pH}$ values. As such, it was necessary to adjust the drink matrices to more alkaline $\mathrm{pH}$ values to facilitate detection. By diluting the drink samples in a 1:1 ratio with the electrolyte recoveries of $99 \%$ and $96 \%$ were obtained for Coca-Cola, and tonic, respectively. This demonstrated a high degree of accuracy, with the ECL sensor producing recoveries above the 95\% threshold typically required for analytical methodologies. Analysis of the neat samples demonstrated the ability of the drink matrices to provide the conductivity required to perform electrochemical measurements. As can be seen in Figure 7, the signals obtained from the neat samples displayed a slightly shifted and lower intensity signal. This is likely the consequence of the nonideal characteristics of this matrix, including higher solution resistance to charge transfer. As such, the recoveries obtained for the neat drink samples were below the typical $95 \%$ threshold value at $85 \%$ and $84 \%$ for Coca-Cola and tonic, respectively; concentrations calculated for all samples are reported in Table 2. Previously, Ramdani et al. ${ }^{6}$ have reported the detection of atropine in diluted diet Coca-Cola via CV, but failed to identify atropine in tonic water as a result of interference from the electroactive alkaloid, quinine. As shown in Figure $7 \mathrm{~b}$, the influence of quinine can be almost negated by the employment of ECL alongside CV. The diluted tonic water displayed no significant interference from quinine at $\mathrm{pH} 8$. However, it is likely that at alternative $\mathrm{pH}$ values a greater interference effect could be observed. The nonspiked neat tonic water displays a larger signal compared with the diluted 

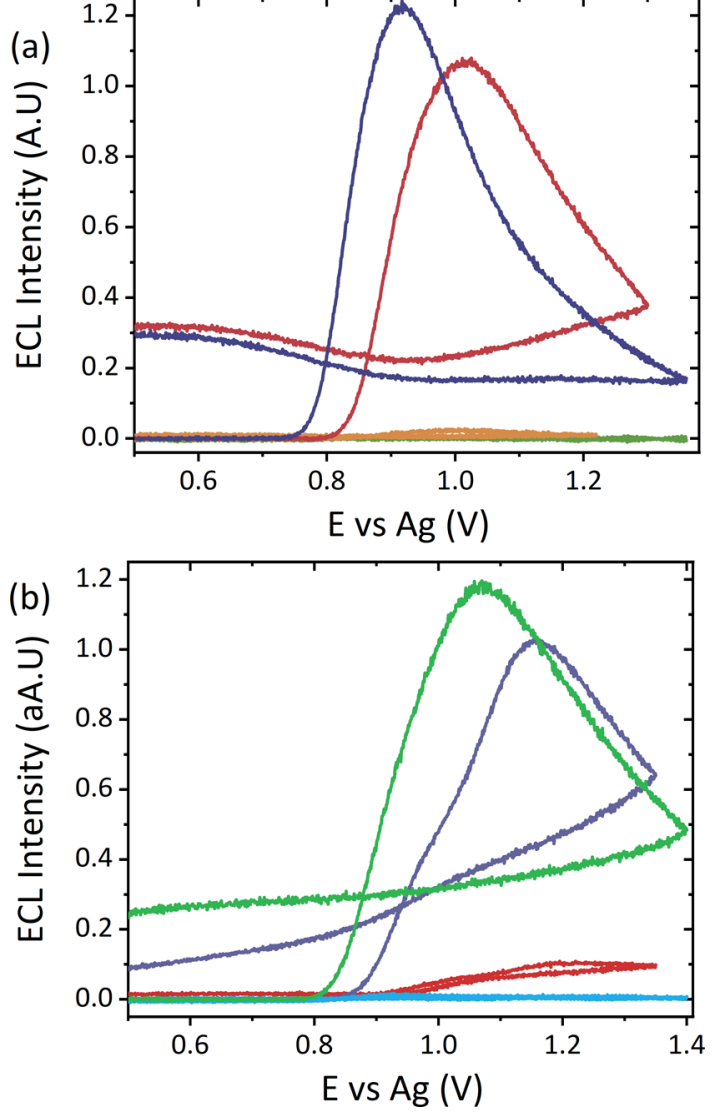

Figure 7. (a) ECL responses obtained for neat $\mathrm{pH} 8$ Coca-Cola (orange), $\mathrm{LiClO}_{4}$ diluted $\mathrm{pH} 8$ Coca-Cola (lime), neat $\mathrm{pH} 8$ CocaCola spiked with $50 \mu \mathrm{M}$ atropine sulfate (pink), and $\mathrm{LiClO}_{4}$ diluted $\mathrm{pH} 8$ Coca-Cola spiked with $50 \mu \mathrm{M}$ atropine sulfate (purple) with a $\left[\mathrm{Ru}(\mathrm{bpy})_{3}\right]^{2+}$-modified electrode at a scan rate of $100 \mathrm{mV} \mathrm{s}^{-1}$ over the potential range $0.5 \leq \nu \leq 1.36 \mathrm{~V}$ vs Ag at a PMT setting of $0.45 \mathrm{~V}$. (b) ECL responses obtained for neat $\mathrm{pH} 8$ tonic water (red), $\mathrm{LiClO}_{4}$ diluted $\mathrm{pH} 8$ tonic water (blue), neat $\mathrm{pH} 8$ tonic water spiked with $50 \mu \mathrm{M}$ atropine sulfate (purple), and $\mathrm{LiClO}_{4}$ diluted $\mathrm{pH} 8$ tonic water spiked with $50 \mu \mathrm{M}$ atropine sulfate (green) with $\left[\mathrm{Ru}(\mathrm{bpy})_{3}\right]^{2+}$ modified electrode at a scan rate of $100 \mathrm{mV} \mathrm{s}^{-1}$ over the potential range $0.5 \leq \nu \leq 1.4 \mathrm{~V}$ vs $\mathrm{Ag}$ at a PMT setting of $0.45 \mathrm{~V}$.

Table 2. Calculated Atropine Sulfate Concentrations and \% Recoveries Obtained from ECL Analysis of Spiked pH 8 Coca-Cola and Tonic Water Samples

\begin{tabular}{lcc}
\multicolumn{1}{c}{ sample } & avg concn calcd $(\mu \mathrm{M})$ & \% recovery \\
\hline neat Coca-Cola & 42.3 & 85 \\
diluted Coca-Cola & 49.3 & 99 \\
neat tonic water & 42.1 & 84 \\
diluted tonic water & 47.9 & 96 \\
\hline
\end{tabular}

blank. This can likely be attributed to the higher concentration of quinine present in the nondilute sample. This interference effect in combination with the nonideal matrix effects previously discussed could account for the lower recovery obtained within neat tonic water samples. Despite the lower recoveries obtained, this protocol has shown its strength for detection of atropine within nonideal matrices with minimal sample preparation required and, as such, makes an ideal candidate for alternative screening methodologies for employment within a forensic arena. However, the reliance on the $\mathrm{pH}$ of samples does present a significant limitation to the proposed protocol for field employment, where the ability to accurately adjust samples to a specified $\mathrm{pH}$ would be challenging. As a screening protocol, however, the ability to accurately quantify samples is not required, and as such, a wide range of $\mathrm{pH}$ values, as shown by Figure 3, would result in an indicative signal, warranting further testing. As such, it is hoped that this protocol would be applicable to a range of different drink matrices across a range of $\mathrm{pH}$ values.

\section{CONCLUSION}

In this work we demonstrated the ability of a simple nafion$\left[\mathrm{Ru}(\mathrm{bpy})_{3}\right]^{2+}$ film modified screen-printed carbon electrode to detect atropine within a variety of complex sample matrices. In spite of the complex nature of the plant-based material, we have observed no significant interference effects, despite the vast number of species present within such material. The developed sensor demonstrates a degree of selectivity toward alkaloid species, with a preference toward tropane alkaloids observed. Although a slight signal is observed for other naturally occurring glycoalkaoids found within herbal material, these signals are negligible compared with the hallucinogenic tropane alkaloids of interest, and as such, these naturally occurring alkaloids can be used as a threshold value above which it can be determined if hallucinogens are present or not. The current methodology, however, does show limited selectivity between different tropane alkaloid species, as is apparent when comparing the emission signals between atropine and scopolamine. Further work is ongoing, with the hope of understanding the impact that scopolamine has on the detected signal within herbal material. However, this initial proof-of-concept demonstrates an appropriate screening method for the identification of hallucinogenic tropane alkaloids within herbal material for the first time via direct analysis of a species within its native form both in mature and young plants via ECL. This proposed protocol would negate the need to perform complex, expensive, and lengthy extraction procedures prior to analysis, making it ideal for field employment. In addition to this, analysis of atropine within complex matrices of Coca-Cola and tonic water, with and without the addition of electrolyte, with good \% recoveries was achieved. Not only does this demonstrate the ability of ECL to be applied to nonideal matrices, but also the ability to detect emission through colored matrices, without any interference effects. These new methodologies would be ideal for future implementation into field analysis where often a rapid result is required with access to limited knowledge or facilities. However, limited selectivity is currently observed between species within the same class, and a dependence on $\mathrm{pH}$ to obtain emission may require samples to be $\mathrm{pH}$-adjusted in-field prior to analysis. Despite this, these initial results have shown promise for the use of ECL sensors for direct detection of species within their native form. This is a concept we are continuing to explore and hope to expand past atropine and scopolamine. Further work is currently investigating potential techniques that could be employed to improve the selectivity of the developed sensor in order to differentiate between compounds within the same class, such as atropine and scopolamine. 


\section{ASSOCIATED CONTENT}

\section{S Supporting Information}

The Supporting Information is available free of charge on the ACS Publications website at DOI: 10.1021/acs.analchem.9b02905.

$\mathrm{CV}$ of atropine sulfate at high concentrations on unmodified electrodes (Figure S1), CV and ECL responses for $50 \mu \mathrm{M}$ tropine and tropic acid in $\mathrm{pH} 8$

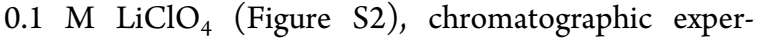
imental details (Table S1) and corresponding chromatograms (Figure S3), corresponding $\mathrm{CV}$ of mechanical application of plant material in Figure 5 (Figure S5) and $\mathrm{CV}$, and corresponding ECL signals from raw and spiked raw Coca-Cola and tonic water (Figure S5) (PDF)

\section{AUTHOR INFORMATION}

\section{Corresponding Author}

*E-mail: lynn.dennany@strath.ac.uk.

\section{ORCID}

Lynn Dennany: 0000-0002-5481-1066

\section{Author Contributions}

The manuscript was written through contributions of all authors.

\section{Notes}

The authors declare no competing financial interest.

All data underpinning this publication are openly available from the University of Strathclyde KnowledgeBase at https:// doi.org/10.15129/f678fa16-df1e-47b1-ba25-0a0728f6b9f5.

\section{ACKNOWLEDGMENTS}

The authors would like to acknowledge The Carnegie Trust for the Universities of Scotland for the Ph.D. scholarship funding that has supported this work and the AHRC AH/ M008894/1.

\section{REFERENCES}

(1) Tettey, J.; Crean, C. Philos. Trans. R. Soc., B 2015, 370, 20140265.

(2) Shaw, L.; Dennany, L. Curr. Opin. Electrochem. 2017, 3, 23-28.

(3) World Drug Report 2018, United Nations Publications, 2018.

(4) Banks, C.; Smith, J. Analytical Scientist 2016, 41-43.

(5) Reichert, S.; Lin, C.; Ong, W.; Him, C. C.; Hameed, S. Canadian family physician Medecin de famille canadien 2017, 63, 369-370.

(6) Ramdani, O.; Metters, J. P.; Figueiredo-Filho, L. C. S.; FatibelloFilho, O.; Banks, C. E. Analyst 2013, 138, 1053-1059.

(7) Srivanitchapoom, P.; Pandey, S.; Hallett, M. Parkinsonism \& related disorders 2014, 20, 1109-1118.

(8) Gwiazda, J. Optometry and vision science: official publication of the American Academy of Optometry 2009, 86, 624-628.

(9) Eddleston, M.; Buckley, N. A.; Eyer, P.; Dawson, A. H. Lancet 2008, 371, 597-607.

(10) Johnson, D. Chemistry World; Royal Society of Chemsitry, 2013

(11) Dräger, B. J. Chromatogr. A 2002, 978, 1-35.

(12) Auriola, S.; Martinsen, A.; Oksman-Caldentey, K.-M.; Naaranlahti, T. J. Chromatogr., Biomed. Appl. 1991, 562, 737-744.

(13) Namera, A.; Yashiki, M.; Hirose, Y.; Yamaji, S.; Tani, T.; Kojima, T. Forensic Sci. Int. 2002, 130, 34-43.

(14) Li, J.; Chun, Y.; Ju, H. Electroanalysis 2007, 19, 1569-1574.

(15) Yuan, B.; Zheng, C.; Teng, H.; You, T. J. Chromatogr. A 2010, $1217,171-174$

(16) Yang, X.-Y.; Xu, C.-Y.; Yuan, B.-Q.; You, T.-Y. Chin. J. Anal. Chem. 2011, 39, 1233-1237.
(17) Zhang, A.; Miao, C.; Shi, H.; Xiang, H.; Huang, C.; Jia, N. Sens. Actuators, B 2016, 222, 433-439.

(18) Atta, N. F.; Galal, A.; Ahmed, R. A. Int. J. Electrochem. Sci. 2012, 7, 10365-10379.

(19) Bagheri, H.; Arab, S. M.; Khoshsafar, H.; Afkhami, A. New J. Chem. 2015, 39, 3875-3881.

(20) Ensafi, A. A.; Nasr-Esfahani, P.; Heydari-Bafrooei, E.; Rezaei, B. Talanta 2015, 131, 149-155.

(21) Leroy, P.; Nicolas, A. J. Pharm. Biomed. Anal. 1987, 5, 477484.

(22) Dar, R. A.; Brahman, P. K.; Tiwari, S.; Pitre, K. S. Colloids Surf., B 2012, 91, 10-17.

(23) Xiang, Q.; Yang, X. D.; Gao, Y. Adv. Mater. Res. 2014, 989994, 1007-1010.

(24) Gao, Y.; Tian, Y.; Wang, E. Anal. Chim. Acta 2005, 545, 137141.

(25) Bard, A. J.; Faulkner, L. R.; Leddy, J.; Zoski, C. G. Electrochemical Methods: Fundamentals and Applications; Wiley: New York, 1980; Vol. 2.

(26) O’Reilly, E. J.; Keyes, T. E.; Forster, R. J.; Dennany, L. Analyst 2013, 138, 677-682.

(27) Rubinstein, I.; Bard, A. J. J. Am. Chem. Soc. 1980, 102, 66416642 .

(28) Rubinstein, I.; Bard, A. J. J. Am. Chem. Soc. 1981, 103, 50075013.

(29) Qu, Y.; Liu, X.; Zheng, X.; Guo, Z. Anal. Sci. 2012, 28, 571576.

(30) O’Reilly, E. J.; Keyes, T. E.; Forster, R. J.; Dennany, L. Electrochem. Commun. 2018, 86, 90-93.

(31) Xu, Y.; Gao, Y.; Wei, H.; Du, Y.; Wang, E. J. Chromatogr. A 2006, 1115, 260-266.

(32) Song, C.; Zhang, J. In PEM Fuel Cell Electrocatalysts and Catalyst Layers: Fundamentals and Applications; Zhang, J., Ed.; Springer: London, 2008; pp 89-134.

(33) Cai, Q.; Chen, L.; Luo, F.; Qiu, B.; Lin, Z.; Chen, G. Anal. Bioanal. Chem. 2011, 400, 289-294.

(34) Meti, M. D.; Nandibewoor, S. T.; Chimatadar, S. A. Synth. React. Inorg., Met.-Org., Nano-Met. Chem. 2014, 44, 263-272.

(35) McGeehan, J.; Dennany, L. Forensic Sci. Int. 2016, 264, 1-6.

(36) Takahashi, F.; Nitta, S.; Shimizu, R.; Jin, J. Forensic Toxicol. 2018, 36, 185-191.

(37) Forster, R. J.; Hogan, C. F. Anal. Chem. 2000, 72, 5576-5582.

(38) Rosenheim, O. Analyst 1907, 32, 106b-108.

(39) Portis, L. C.; Bhat, V. V.; Mann, C. K. J. Org. Chem. 1970, 35, $2175-2178$

(40) Laube, B. L.; Asirvatham, M. R.; Mann, C. K. J. Org. Chem. 1977, 42, 670-674.

(41) Dettbarn, W. D.; Heilbronn, E.; Hoskin, F. C. G.; Kitz, R. Neuropharmacology 1972, 11, 727-732.

(42) Zvirblis, P.; Socholitsky, I.; Kondritzer, A. A. J. Am. Pharm. Assoc., Sci. Ed. 1956, 45, 450-454.

(43) Greenwood, P. A.; Merrin, C.; McCreedy, T.; Greenway, G. M. Talanta 2002, 56, 539-545.

(44) Boros, B.; Farkas, Á.; Jakabová, S.; Bacskay, I.; Kilár, F.; Felinger, A. Chromatographia 2010, 71, 43-49.

(45) Oja, S. M.; Zhang, B. ChemElectroChem 2016, 3, 457-464.

(46) Shen, L.-H.; Wang, H.-N.; Chen, P.-J.; Yu, C.-X.; Liang, Y.-D.; Zhang, C.-X. J. Food Drug Anal. 2016, 24, 199-205.

(47) Friedman, M. J. Chromatogr. A 2004, 1054, 143-155. 